\title{
A Study of Artifacts on Hyoid Bone, Sent for Expert Opinion to Department of Forensic Medicine, Guntur Medical College, Guntur
}

\author{
Dr.P.Chandrasekhararao M.D ${ }^{1}$ Dr.V.Sivakameswararao \\ M.D ${ }^{2}$ Dr.A.Rameshbabu M.D ${ }^{3}$ Dr.Krishnamurthy M.D ${ }^{4}$ \\ ${ }^{I}$ Associate Professor Department OfForensic Medicine Guntur Medical College, Guntur. \\ ${ }^{2,3,4}$ Assistant Professor Department Of Forensic Medicine Guntur Medical College, Guntur
}

\begin{abstract}
The examination of the hyoid bone in mechanical asphyxial death has a lot of medico legal importance. Most of the studies regarding hyoid bone are related to fractures of bone in cases of hanging, strangulation and throttling, throwing a little light over the artifacts of hyoid bone. Artifacts may be misinterpreted as medico legally significant ante mortem findings. So, the autopsy pathologist should be able to distinguish the artifacts from the significant ante mortem changes. Faulty use of preservatives can cause toxologicalartifacts over hyoid bone. Hence in this study a more detailed study of hyoid bone in cases of mechanical asphyxial deaths regarding artifacts over it was attempted. After analysis it was found that unconventional usage of preservatives is producing accentuated artifactual effects on the hyoid.
\end{abstract}

Keywords: Hyoid bone, Artifacts, Preservatives, Fractures.

\section{Introduction}

The hyoid bone is a unique structure in the body, situated in the upper part of the neck, above the thyroid cartilage and is notdirectly associated with any other bone and is suspended in the neck by the ligaments attached to skull by stylohyoid ligament.

Observation of hyoid bone is one of most integral and intriguing part of internal examination during autopsy of mechanical asphyxia deaths due to pressure over the neck.

Artifacts are any changes caused or features introduced in a body after death, that is likely to lead to misinterpretation of medico legally significant ante mortem findings. The responsibility of the doctor during autopsy is very great and the autopsy pathologist should be able to distinguish the artifacts from the significant ante mortem changes. If the doctor misinterprets the artifacts, during cross examination in the court the lawyer may attempt to discredit his evidence.

As most of the previous studies over hyoid bone are related and restricted to fractures of bone in cases of hanging, strangulation and throttling, throwing a little light over the artifacts of hyoid bone. The present study was attempted to observe the toxicological artifacts developed over hyoid bone due to faulty usage of preservatives in cases of mechanical asphyxia deaths.

\section{Materials and methods:}

The materials used for this study were the hyoid bones which were sent to department of forensic medicine, Guntur Medical College, Guntur from the peripheral hospitals of Guntur and Prakasam districts for expert opinion.

In the present study 100 hyoid bones were collected and examined over a period of two years. After the dissection of the soft tissues, the hyoid bones were examined with the help of magnifying method to ascertain the artifacts present over the examined hyoid bone. Study of the artifacts with regards to preservative used was also ascertained. The examined hyoid bones were photographed.

\section{Observation and results:}

Out of 100 samples, preservative used was Nacl in 64 cases, formalin in 31 cases and surgical spirit in 5 cases. Usage of unconventional preservative and abnormal delay in sending the hyoid bone for expert opinion accounts for increased artifactual changes of hyoid bones. As per as fracture related cases are concerned it could be assumed that faulty technique of dissection for removal of hyiod bone were responsible for artifactual changes. In the present study, artifacts were noticed in 28 samples out of 100 samples. Types of artifacts noticed were separation(14), loosening(7), perimortam fracture(4) and dislocation(3). Highest number of artifacts that is 26 were noticed in samples which used common salt solution as preservative, out of which 14 were separation, 7 were loosening, 3 were perimortam fracture and 2 were dislocation. All the cases of loosening and separation were seen with usage of common salt as preservative. 
Data showing the preservative used for hyoid bone

samples
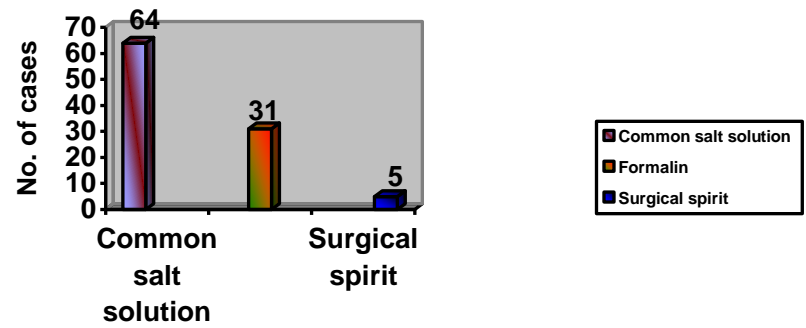

Preservatives used

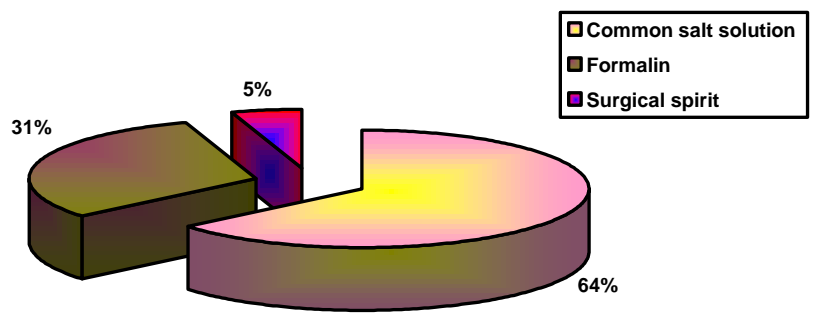

VIII.Numberand type of artifacts related to nature of the preservative used.

\begin{tabular}{|l|l|l|l|l|l|}
\hline & Dislocations & PM. Fracture & Loosening & Separation & Total \\
\hline Formalin & 0 & 1 & 0 & 0 & $\mathbf{1}$ \\
\hline $\begin{array}{l}\text { Common salt } \\
\text { solution }\end{array}$ & 2 & 3 & 7 & 14 & $\mathbf{2 6}$ \\
\hline Surgical spirit & 1 & 0 & 0 & 0 & $\mathbf{1}$ \\
\hline Total & $\mathbf{1}$ & $\mathbf{4}$ & $\mathbf{7}$ & $\mathbf{1 4}$ & $\mathbf{2 8}$ \\
\hline
\end{tabular}

IX Artifacts present over the hyoid bones in referred cases for expert opinion from peripheral hospitals

\begin{tabular}{|l|l|l|l|l|l|l|}
\hline $\begin{array}{l}\text { Total no of } \\
\text { hyoid bones } \\
\text { examined }\end{array}$ & $\begin{array}{l}\text { Total no. of } \\
\text { mechanical } \\
\text { asphyxial deaths }\end{array}$ & Dislocations & $\begin{array}{l}\text { PM } \\
\text { fractures }\end{array}$ & Separation & Loosening & Total \\
\hline 100 & 42 & $\begin{array}{l}3 \\
(10.71)\end{array}$ & $\begin{array}{l}4 \\
(14.28 \%)\end{array}$ & $\begin{array}{l}14 \\
(50 \%)\end{array}$ & $\begin{array}{l}7 \\
(25 \%)\end{array}$ & 28 \\
\hline
\end{tabular}

\section{TYPE OF ARTIFACTS PRESENT OVER HYOID BONE}

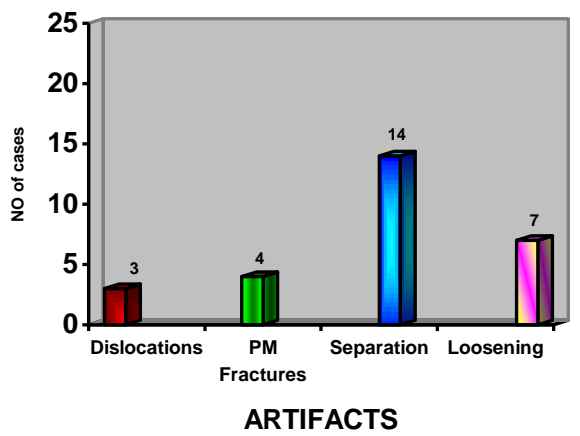

$\square$ Dislocation
$\square$ PM Fractures
$\square$ Separation
$\square$ Loosening




\section{TYPE OF ARTIFACT}

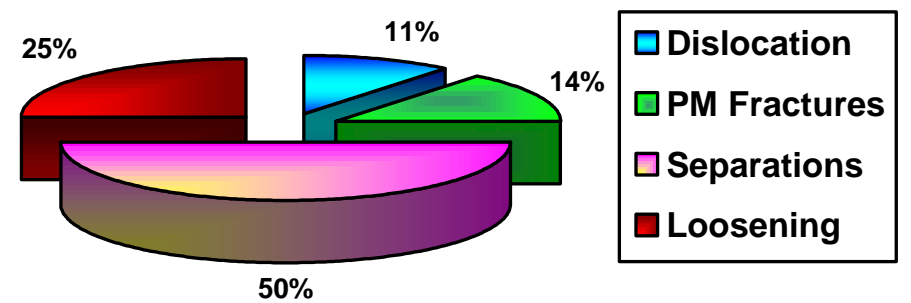

Separation of all the joints of hyoid bone- with the use of rectified spirit as preservative.

..

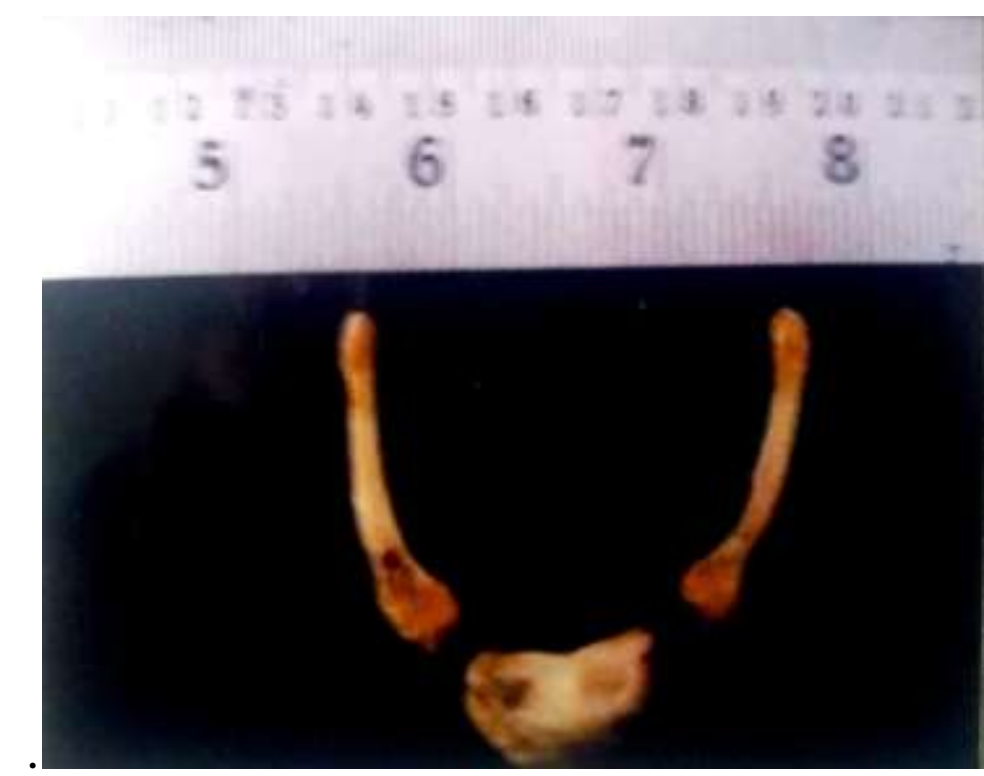

Loosening of all the joints of hyoid bone- with the use of common salt solution as preservative

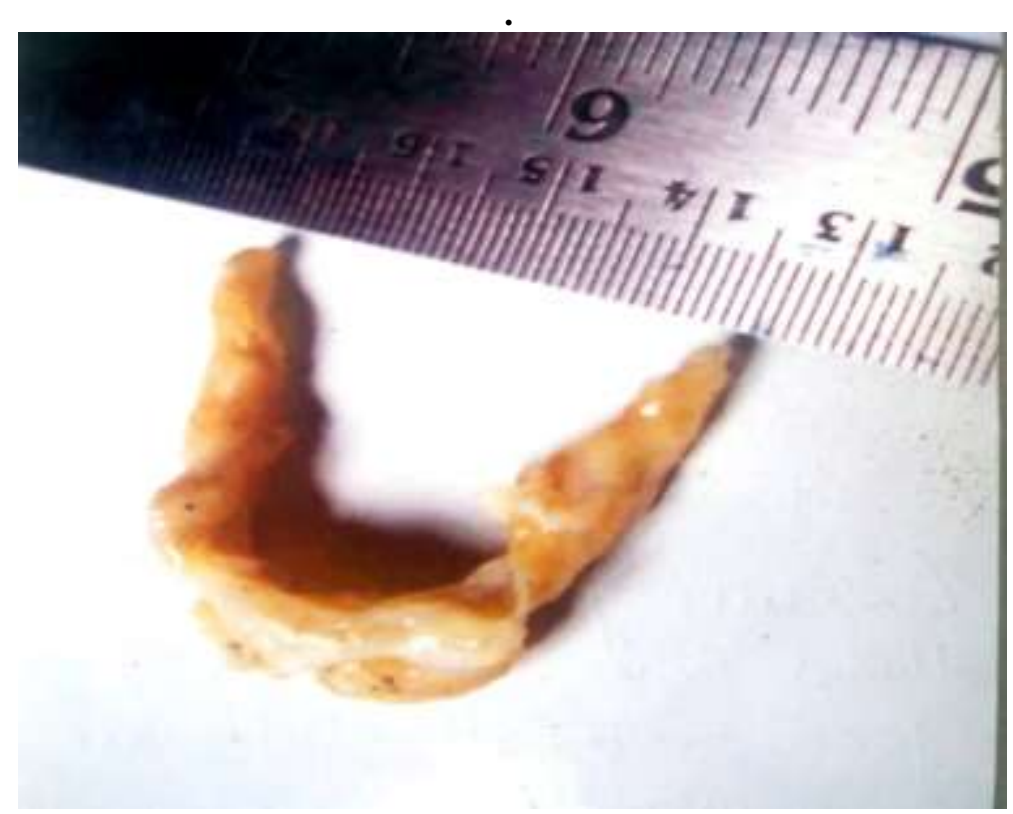


Fixation of all the joints of hyoid bone- with the use of formalin as preservative

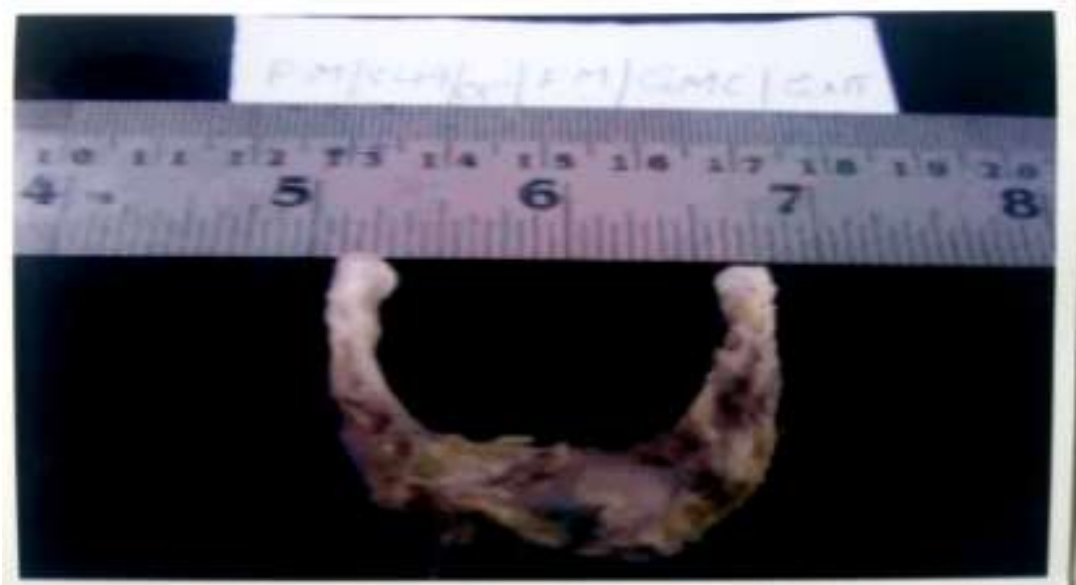

\section{Conclusion}

Unconventional use of preservativeslike common salt solution are producing accentuated artifactualeffects on the hyoid bone. Furthermore undue delay in sending the samples, faulty techniques of dissection of hyoid bone, rough handling of the specimen and forcible introduction of specimen into a narrow spaced bottle are creating an added problem in giving the expert opinion. In our research we have found FORMALIN to be the best preservative one can use without causing much artifacts to a given specimen.

Most of the doctors working at peripheral hospitals are not qualified forensic experts and they are not expected to know about all the details of forensic medicine, hence the problem of sending hyoid bone by using unconventional preservative is arising. Hence any amount of efforts which enlighten the doctors working at peripheral hospital regarding the usage of conventional preservative in prescribed concentration and regarding the precautions to be taken while dissecting out the hyoid bone and packing them for sending to expert opinion and the need to arrange special training classes in this aspect for doctors working at periphery need to be over stressed.

\section{References}

[1]. The essentials of Forensic Medicine-C.J.Polson, D.J. Gee and B.Knight- Fourth Edition.

[2]. Knight's -Forensic Pathology - Third Edition.

[3]. The essentials of Forensic Medicine and Toxicology -Dr.K.S.Narayana Reddy - Eighteenth Edition.

[4]. Hand book of Forensic Medicine and Toxicology -Dr. K.Krishna Reddy - Eighth Edition.

[5]. Text book of Human Osteology-Inderbirsingh - Second Edition - Reprint - 2005

[6]. Hand book of Osteology.-Dr. S.Poddar - Eleventh Edition.

[7]. A colour atlas of human Anatomy-R.M.H.McMinn, R.T. Hutchings - Second Edition.

[8]. Human Embryology-InderbirSingh - Sixth Edition.

[9]. Text book of Forensic Medicine and Toxicology - KrishanVij - Third Edition - 2005

[10]. Parikhs text book of Medical Jurisprudence, Forensic Medicine and Toxicology - Dr.C.K.Parikh - Sixth Edition - Reprint - 2000

[11]. Modi's Medical Jurisprudence and Toxicology -Edited by B.V.Subramanyam - Second Edition - 2001.

[12]. Principles of Forensic Medicine-ApurbaNandy - Reprint - Second Edition - 2000. 